\title{
Structure and dehydration mechanism of the proton conducting oxide $\mathrm{Ba}_{2} \ln _{2} \mathrm{O}_{5}\left(\mathrm{H}_{2} \mathrm{O}\right)_{x}$
}

\author{
Johan Bielecki, Stewart F. Parker, Laura Mazzei, \\ Lars Börjesson and Maths Karlsson
}

\section{Published version information}

Citation: Bielecki J, Parker SF, Mazzei L, Börjesson L and Karlsson M. "Structure and dehydration mechanism of the proton conducting oxide $\mathrm{Ba}_{2} \mathrm{In}_{2} \mathrm{O}_{5}\left(\mathrm{H}_{2} \mathrm{O}\right) \times$ ". Journal of Materials Chemistry A, issue 4 (2016): 1224-1232.

doi: $\underline{10.1039 / C 5 T A 05728 K}$

This version is made available in accordance with publisher policies. Please cite only the published version using the reference above. 


\title{
Structure and dehydration mechanism of the proton conducting oxide $\mathbf{B a}_{2} \mathbf{I n}_{2} \mathbf{O}_{5}\left(\mathbf{H}_{2} \mathbf{O}\right)_{x}$
}

\author{
Johan Bielecki ${ }^{1,2}$, Stewart F. Parker ${ }^{3}$, Laura Mazzei ${ }^{1}$, Lars Börjesson ${ }^{1}$, Maths Karlsson ${ }^{1, *}$
}

The structure and dehydration mechanism of the proton conducting oxide $\mathrm{Ba}_{2} \mathrm{In}_{2} \mathrm{O}_{5}\left(\mathrm{H}_{2} \mathrm{O}\right)_{x}$ are investigated by means of variable temperature $\left(20-600{ }^{\circ} \mathrm{C}\right)$ Raman spectroscopy together with thermal gravimetric analysis and inelastic neutron scattering. At room temperature, $\mathrm{Ba}_{2} \mathrm{In}_{2} \mathrm{O}_{5}\left(\mathrm{H}_{2} \mathrm{O}\right)_{x}$ is found to be fully hydrated $(x=1)$ and to have a perovskite-like structure, which dehydrates gradually with increasing temperature and at around $600{ }^{\circ} \mathrm{C}$ the material is essentially dehydrated $(x \approx 0.2)$. The dehydrated material exhibits a brownmillerite structure, which is featured by alternating layers of $\mathrm{InO}_{6}$ octahedra and $\mathrm{InO}_{4}$ tetrahedra. The transition from a perovskite-like to a brownmillerite-like structure upon increasing temperature occurs through the formation of an intermediate phase at $c a .370{ }^{\circ} \mathrm{C}$, corresponding to a hydration degree of approximately $50 \%$. The structure of the intermediate phase is similar to the structure of the dehydrated material, but with the difference that it exhibits a non-centrosymmetric distortion of the $\mathrm{InO}_{6}$ octahedra that is not present in the dehydrated material. The dehydration process upon heating is a two-stage mechanism; for temperatures below the hydrated-to-intermediate phase transition, dehydration is characterized by a homogenous release of protons over the entire oxide lattice, whereas above the transition a preferential desorption of protons originating in the nominally tetrahedral layers is observed. Furthermore, our spectroscopic results point towards the co-existence of two structural phases, which relate to the two lowest-energy proton configurations in the material. The relative contributions of the two proton configurations depend on how the sample is hydrated.

\section{Introduction}

Proton conducting oxides are currently the subject of considerable attention due to their significant potential as efficient proton conducting electrolytes in next-generation, intermediatetemperature $\left(\approx 200-500{ }^{\circ} \mathrm{C}\right)$ solid oxide fuel cells (SOFC). ${ }^{1,2}$ Amongst the most studied and promising materials is barium indate, $\mathrm{Ba}_{2} \mathrm{In}_{2} \mathrm{O}_{5}$, which has a brownmillerite type structure, named after the original $\mathrm{Ca}_{2} \mathrm{FeAlO}_{5}$ mineral. ${ }^{3}$ The brownmillerite structure may be described as an oxygen deficient variant of the more well-known perovskite structure and exhibits alternating layers of $\mathrm{InO}_{6}$ octahedra and $\mathrm{InO}_{4}$ tetrahedra; for recent structural studies of $\mathrm{Ba}_{2} \mathrm{In}_{2} \mathrm{O}_{5}$ and its variants see refs. ${ }^{4-10}$ As shown in Fig. 1(a), the octahedral layers contain the $\operatorname{In}(1)$ and $\mathrm{O}(1)$ atomic positions and the tetrahedral layers contain the $\operatorname{In}(2)$ and $\mathrm{O}(3)$ atomic positions, with the two types of layers bridged by the apical oxygens, denoted $\mathrm{O}(2)$. There is no orientational order between successive layers. ${ }^{7}$

Like many other oxygen deficient oxides, $\mathrm{Ba}_{2} \mathrm{In}_{2} \mathrm{O}_{5}$ transforms upon hydration into a hydrogen containing, proton conducting, material. Hydration is generally carried out by heat treatment in a humid atmosphere, a process during which the

\footnotetext{
${ }^{1}$ Department of Applied Physics, Chalmers University of Technology, SE-412 96 Göteborg, Sweden. Fax: +46 31772 2090; Tel: +46 31772 8038; E-mail: maths.karlsson@chalmers.se (Maths Karlsson).

${ }^{2}$ Department of Cell and Molecular Biology, Uppsala University, Box 596, SE-75124 Uppsala, Sweden.

${ }^{3}$ ISIS Facility, STFC Rutherford Appleton Laboratory, Chilton, Didcot, Oxon OX11 0QX UK.
}

water molecules in the gaseous phase dissociate into hydroxyl groups $\left(\mathrm{OH}^{-}\right)$and protons $\left(\mathrm{H}^{+}\right)$on the surface of the sample. The hydroxyl groups then occupy nearby oxygen vacancies, whilst the remaining protons bind to lattice oxygens of the oxide host lattice. The protons, however, are not stuck to any particular oxygen atoms, but are free to move from one oxygen to another and, with time, they will therefore diffuse into the bulk of the material. At the same time as protons diffuse into the bulk, the counter diffusion of oxygen vacancies from the bulk to the surface allows the dissociation of other water molecules on the surface of the sample. This leads to an increase of the proton concentration in the material and so it is believed that the process continues until the (bulk) oxygen vacancies are filled, leading, ideally, to a material of the form $\mathrm{BaInO}_{3} \mathrm{H}$.

The structure of $\mathrm{BaInO}_{3} \mathrm{H}$ is not a brownmillerite, but may be described as a perovskite-like structure with successive, distinctly different, layers of $\mathrm{InO}_{6}$ octahedra running along the $c$-direction of an orthorhombic unit cell, cf. Fig. 1 (b-c). The orthorhombic arrangement can be expected to be due to proton ordering, as opposed to protons being randomly distributed over the oxide lattice. Neutron diffraction analysis has shown that the average structure contains two different proton sites; one of which lies on the midpoint between $\mathrm{O}(1)$ atoms within the octahedral layer and the other one which refers to a position in the plane formed by the apical $\mathrm{O}(2)$ oxygens, described by the $2 c$ and $16 l$ Wyckoff positions, respectively. ${ }^{12}$ Using these results as a starting point for structural optimizations by means of first-principles calculations, Martinez et al. ${ }^{11}$ and 

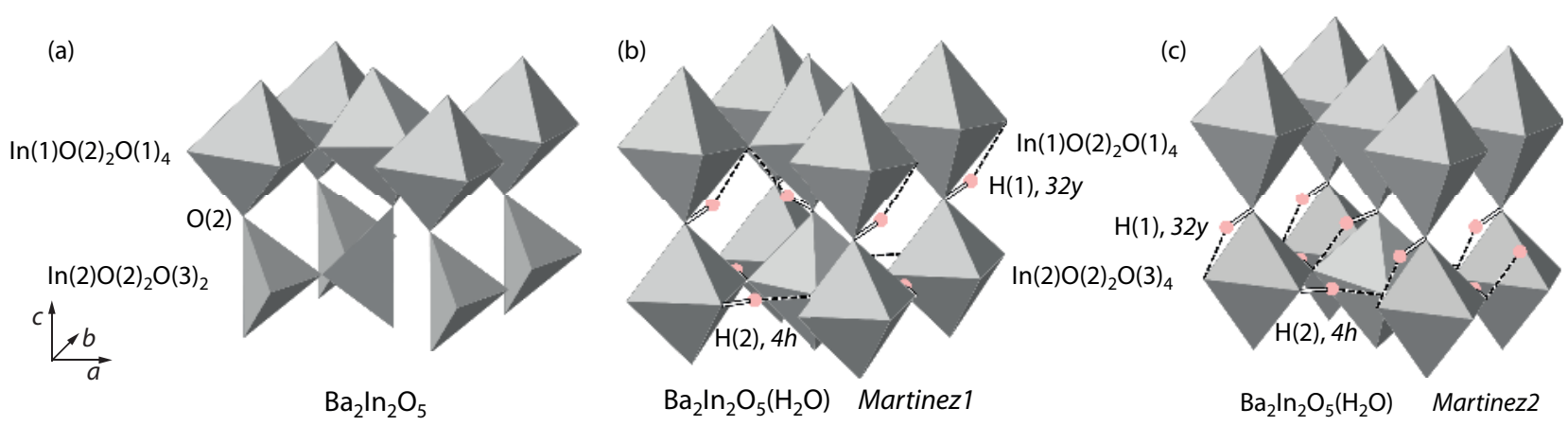

Fig. 1 Schematic illustration of the structure of $\mathrm{Ba}_{2} \mathrm{In}_{2} \mathrm{O}_{5}$ (a) and the two lowest-energy proton configurations in $\mathrm{BaInO}_{3} \mathrm{H}(\mathrm{b}-\mathrm{c})$, according to Martinez et al. ${ }^{11}$. InO polyhedra with oxygens located at the vertices are depicted in grey, and $\mathrm{H}$ by pink spheres. Covalent $\mathrm{O}-\mathrm{H}$ bonds are indicated by solid grey lines, and hydrogen bonds are indicated by dashed lines. Ba atoms are omitted for simplicity.

Dervişoğlu et al. ${ }^{5}$ both investigated the possible local proton configurations and found that the $16 \mathrm{l}$ protons are, in a more realistic proton arrangement, described by the $32 y$ position and that the $2 c$ protons are described by the $4 h$ position, where $4 h$ and $32 y$ represent local deviations from the average $2 c$ and $16 l$ positions. ${ }^{11}$ Specifically, the $4 h$ position refers to protons which we here denote as $\mathrm{H}(2)$ and which are bonded to inplane oxygens, $\mathrm{O}(3)$, whereas the $32 y$ position refers to protons which we denote as $\mathrm{H}(1)$ and which are bonded to the apical oxygens, $\mathrm{O}(2), c f$. Fig. 1(b). Upon dehydration the $\mathrm{O}(3)$ octahedra transform into tetrahedra, while the $\mathrm{O}(1)$ octahedra remain as such. Both of the theoretical studies found two local structures (proton configurations), labeled Martinezl and Martinez2, as shown in Fig. 1(b) and (c), with lower energies compared to a range of other proton configurations also considered in the structural optimizations. The two studies do not, however, agree on the ground-state structure: whereas Martinez et al. ${ }^{11}$ assigned the ground-state structure to the Martinezl proton configuration, Dervişoğlu et al. ${ }^{5}$ found that Martinez2 was of lowest energy. The two local structures are conceptually similar, with equally many protons in the $4 h$ and $32 y$ positions, respectively, and where the only difference between them relates to the hydrogen-bond pattern of the $32 y$ protons. In the Martinez 1 structure, the $32 y$ protons are hydrogen bonded towards the $\mathrm{O}(1)$ layer, whereas in the Martinez2 structure the $32 y$ protons are hydrogen bonded to the $\mathrm{O}(3)$ oxygens. Recently, it was shown that the hydrogen bonding of the $32 y$ protons in the Martinezl structure has the effect of pulling the $\mathrm{O}(1)$ oxygen towards the $\mathrm{H}(1)$ site, which gives rise to a long-range non-centrosymmetric distortion of the $\operatorname{In}(1) \mathrm{O}_{6}$ octahedra. ${ }^{7}$ Further, Dervişoğlu et al. ${ }^{5}$ measured the ${ }^{1} \mathrm{H}$ NMR spectra of $\mathrm{BaInO}_{3} \mathrm{H}$, which suggested the presence of three distinct proton positions in the structure. The three positions correspond to one position within the $\mathrm{O}(3)$ layer, and two positions within the $\mathrm{O}(2)$ layer that hydrogen bonds to either the $\mathrm{O}(3)$ or $\mathrm{O}(1)$ layer, respectively. First-principles calculations could reproduce the ${ }^{1} \mathrm{H}$ NMR experiments by including four low-energy proton configurations within the material. ${ }^{5}$ Each of these configurations, labeled I, J K, and L, is a specific combination of proton occupations on the three positions mentioned above. ${ }^{5}$ Similarities in hydrogen-bond patterns and crystal distortions make it possible to associate, with regards to vibrational fingerprints, I and $\mathrm{K}$ as "Martinezl-like" proton configurations, whereas $\mathrm{J}$ and $\mathrm{L}$ can be regarded as "Martinez2-like".

While the structures of the fully dehydrated and fully hydrated structures have emerged recently, ${ }^{7}$ little is known about the structure for intermediate proton loadings, i.e. for partially hydrated structures, and in particular about the dehydration mechanism, which relates to the proton dynamics and therefore to the materials' proton conducting properties. In this context, it has been suggested recently that the full occupation of $\mathrm{H}(2)$ protons on the $4 h$ site may hinder the diffusion of protons within the $\operatorname{In}(2)-\mathrm{O}(3)$ plane containing the nearest oxygen neighbors to which the $\mathrm{H}(2)$ protons form strong hydrogen bonds, and therefore that the proton conductivity may be governed instead by the more weakly hydrogen bonded $\mathrm{H}(1)$ protons on the $32 y$ site. $^{7}$ However, upon dehydration with increasing temperature it might be that the diffusivity of $\mathrm{H}(2)$ protons increases at a rate that is a function of the $\mathrm{H}(2)$ occupancy, and if so, the question is whether there is an optimum occupancy? Such information is not only of purely academic interest, but can be expected to help in the development of new, more highly proton conducting oxide systems, which is critical for further development of intermediate-temperature SOFC technology based on proton conducting electrolytes. Accordingly, this work focuses on structural studies of the technologically important material $\mathrm{Ba}_{2} \mathrm{In}_{2} \mathrm{O}_{5}\left(\mathrm{H}_{2} \mathrm{O}\right)_{x}$, with the aim to obtain information about its local structure and how it depends on temperature and degree of hydration, $x$. The in- 
vestigations are performed by means of variable temperature $\left(20-600{ }^{\circ} \mathrm{C}\right)$ Raman spectroscopy together with thermal gravimetric analysis and inelastic neutron scattering (INS). We also discuss our structural results in terms of the mobility of protons and plausible proton conduction mechanisms.

\section{Experimental}

\subsection{Sample preparation}

A powder sample of $\mathrm{Ba}_{2} \mathrm{In}_{2} \mathrm{O}_{5}$ was prepared by solid state sintering by mixing stoichiometric amounts of the starting reactants $\left(\mathrm{BaCO}_{3}\right.$ and $\left.\mathrm{In}_{2} \mathrm{O}_{3}\right)$. The sintering process was divided into three heat treatments: $1000{ }^{\circ} \mathrm{C}$ for $8 \mathrm{~h}, 1200{ }^{\circ} \mathrm{C}$ for 72 $\mathrm{h}$ and $1325{ }^{\circ} \mathrm{C}$ for $48 \mathrm{~h}$, with intermediate cooling, grinding and compacting of pellets between each heat treatment. The as-sintered $\mathrm{Ba}_{2} \mathrm{In}_{2} \mathrm{O}_{5}$ powder was annealed in vacuum at high temperature $\left(\approx 600^{\circ} \mathrm{C}\right)$ in order to remove any protons that the sample may have taken up during its exposure to ambient conditions; this sample is referred to as dehydrated and exhibited essentially the same spectrum as a hydrated sample, $\mathrm{BaInO}_{3} \mathrm{H}$, after heating to $600{ }^{\circ} \mathrm{C}$ in air. A hydrated sample, $\mathrm{BaInO}_{3} \mathrm{H}$, was prepared by annealing a portion of the dehydrated sample at $\approx 300{ }^{\circ} \mathrm{C}$ under a flow of $\mathrm{N}_{2}$ saturated with water vapor for a period of a few days. On the basis of a thermal gravimetric measurement upon heating from 25 to $950{ }^{\circ} \mathrm{C}$ (heating rate $1.5^{\circ} \mathrm{C} / \mathrm{min}$ ), as performed using a $\mathrm{F} 1$ Iris spectrometer from Netzsch, the degree of hydration was determined to be around $110 \%$, i.e. the sample was found to be fully hydrated, see Fig. 2. The fact that the mass loss corresponds to a hydration level slightly higher than $100 \%$ may be related to the presence of a small amount of adsorbed surface water. In agreement with our previous measurements on the same materials, room temperature X-ray powder diffraction patterns for the $\mathrm{Ba}_{2} \mathrm{In}_{2} \mathrm{O}_{5}$ and $\mathrm{BaInO}_{3} \mathrm{H}$ samples suggest an orthorhombic crystal structure for $\mathrm{Ba}_{2} \mathrm{In}_{2} \mathrm{O}_{5}$ and a tetragonal structure for $\mathrm{BaInO}_{3} \mathrm{H}$ with no significant amount of impurities present. ${ }^{7}$

\subsection{Raman spectroscopy}

The Raman spectroscopy experiments were performed in backscattering geometry using a DILOR XY800 spectrometer, equipped with a tunable $\mathrm{Ar}^{+}$laser, a long working distance 40x objective, and a liquid nitrogen cooled CCD detector. The laser was tuned to the green $514 \mathrm{~nm}$ line and the laser power at the sample position was kept at $4 \mathrm{~mW}$ for all measurements. A comparison of the Stokes and anti-Stokes spectra showed negligible laser heating on the sample. All spectra were collected with linearly polarized light impinging on the sample and unpolarized light collected at the CCD, and we used three different experimental setups for our measurements. The 35-720 $\mathrm{cm}^{-1}$ range, covering the vibrational modes of the oxide host

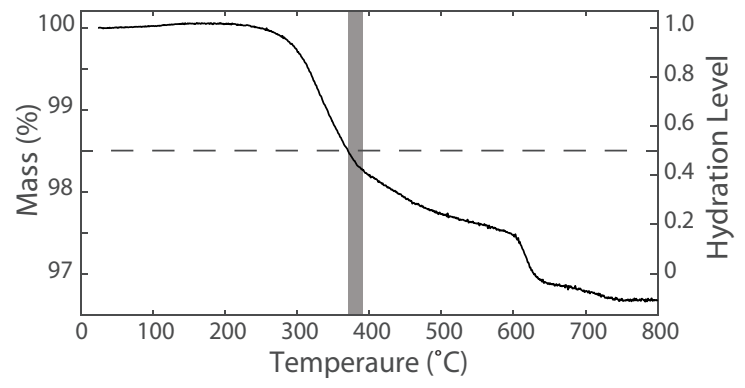

Fig. 2 Thermal gravimetric measurement data of the hydration level as a function of temperature. The hydrated-to-intermediate phase transition is indicated by the shaded area and the $50 \%$ hydration level by the broken line.

lattice, was measured in a high resolution double subtractive mode with a $800 \mathrm{~mm}$ focal distance. The higher-frequency region, $2500-4000 \mathrm{~cm}^{-1}$, covering the $\mathrm{O}-\mathrm{H}$ stretch vibrational modes, was measured with a single grating of $300 \mathrm{~mm}$ focal distance. Variable temperature measurements were performed by measuring in-situ at sequentially higher temperatures. The temperature was controlled by a Linkam heating stage over the range from $20^{\circ} \mathrm{C}$ to $600{ }^{\circ} \mathrm{C}$, with a small opening to prevent overpressure as the sample was dehydrated with increasing temperature. To ensure that the spectra were measured in thermodynamic equilibrium, the sample was held for $1 \mathrm{~h}$ at each temperature before measuring the Raman spectra and, in addition, successive measurements at the same temperature were performed in order to rule out further dehydration after this time. The Raman spectra have been corrected for the BoseEinstein occupation factor and adjusted to a common baseline level. The O-H stretch region of the Raman spectra was further normalized according to the thermal gravimetric curve in order to accurately reflect the total hydrogen content in the sample.

\subsection{Inelastic neutron scattering}

The INS experiment was performed on the fully hydrated sample, $\mathrm{BaInO}_{3} \mathrm{H}$, on MAPS ${ }^{13}$ at $10 \mathrm{~K}$ with an incident energy of $650 \mathrm{meV}$, with the Fermi chopper at 600 and $500 \mathrm{~Hz}$. The sample, approximately 15 grams, was loaded into an aluminium sachet and the sachet into an indium wire sealed thin-walled aluminium can. The measuring time was about one day.

\section{Results and discussion}

\subsection{Structural variability}

While investigating the $20{ }^{\circ} \mathrm{C}$ Raman spectra of $\mathrm{BaInO}_{3} \mathrm{H}$ samples from different sample batches, differing essentially 

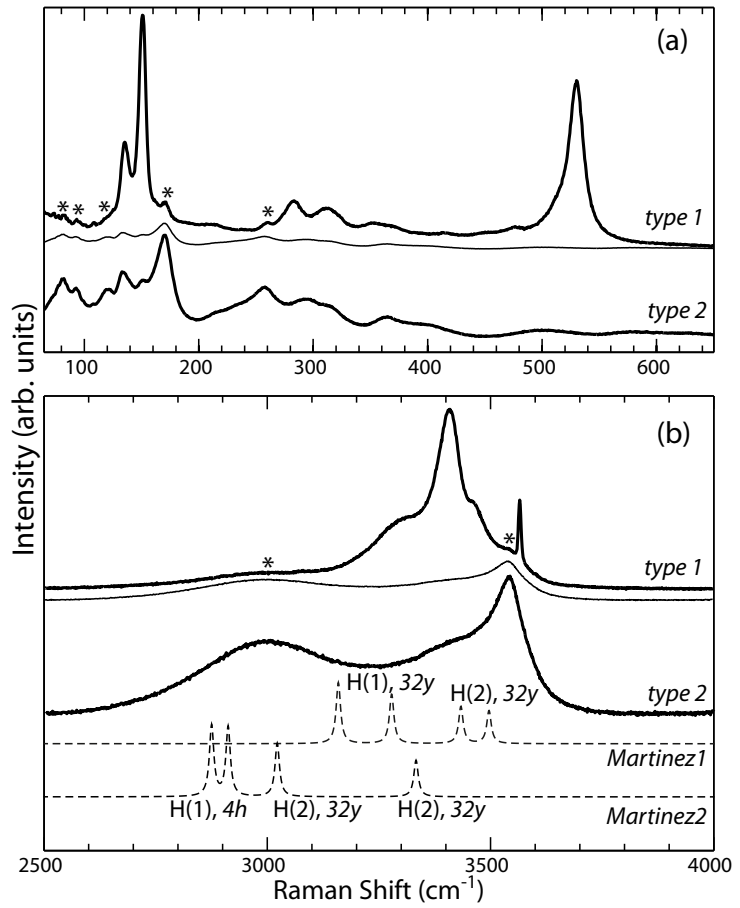

Fig. 3 Comparison of the Raman spectra of $\mathrm{BaInO}_{3} \mathrm{H}$ from different sample batches, illustrating the spectral variations in both (a) the lattice and (b) the $\mathrm{O}-\mathrm{H}$ stretch region of the vibrational spectra. The thin solid line is a rescaled type 2 spectrum that corresponds to the amount of type 2 phase found in the spectrum of predominantly type1. The corresponding impurity peaks are indicated by asterisks, whereas the dashed lines in (b) show the $\mathrm{O}-\mathrm{H}$ stretch frequencies as determined for the two lowest-energy proton configurations as predicted by density functional theory calculations ${ }^{7}$.

in hydration conditions (hydration time and temperature), we observed significant spectral variations. In particular, we found that these variations can be ascribed to different ratios of two distinctly different proton configurations, or phases, which are here denoted as typel and type2. A comparison of the spectra of samples for which either phase is predominant (Fig. 3) suggests that type 2 is generally characterized by a smaller number of bands related to vibrations of the oxide host lattice [Fig. 3(a)], as well as a wider O-H stretch region [Fig. 3(b)]. The former characteristic suggests a more symmetric, although not necessarily ordered, structure, whereas the latter suggests a larger variability in $\mathrm{O}-\mathrm{H}$ distances in the material. Conversely, the narrower $\mathrm{O}-\mathrm{H}$ stretch region in phase typel indicates less structural variability between unit cells, whereas the presence of the sharp, intense, Raman bands at around 150 and $530 \mathrm{~cm}^{-1}$, respectively, is a clear characteristic of a reduction of the symmetry of the local structure.

Included in Fig. 3(b) are also the calculated Raman spectra according to Bielecki et al. ${ }^{7}$, for the two lowest-energy pro- ton configurations found by Martinez et al. ${ }^{11}$ and Dervişoğlu et al. ${ }^{5}$, i.e. the proton configurations that here are called Martinez1 and Martinez2, see Fig. 1. As can be seen, the Martinez 1 configuration corresponds to $\mathrm{O}-\mathrm{H}$ stretch modes in the relatively narrow range from 3100 to $3500 \mathrm{~cm}^{-1}$, which is in agreement with the experimental spectrum of predominantly type 1 . In comparison, the Martinez 2 proton configuration is characterized by $\mathrm{O}-\mathrm{H}$ stretch modes at lower frequencies and is better in agreement with the experimental spectrum of predominantly type 2 . The association of typel with Martinez1-like and type 2 with Martinez-like structures is consistent with the low-frequency Raman spectra [Fig. 3(a)], where the two $150 \mathrm{~cm}^{-1}$ and $530 \mathrm{~cm}^{-1}$ bands, as present only in the type 1 spectrum, can be explained by the non-centrosymmetric $\operatorname{In}(1) \mathrm{O}(2)_{2} \mathrm{O}(1)_{4}$ distortion induced by the $32 y$ hydrogen-bond pattern in the Martinezl proton configuration, as mentioned above. ${ }^{5,11}$ In general, such a structural distortion activates previously inactive Raman modes; in this case an $\operatorname{In}(1)$ mode at $150 \mathrm{~cm}^{-1}$ and an $\operatorname{In}(1)-\mathrm{O}$ stretch mode at $530 \mathrm{~cm}^{-1}$. One should note, however, that there is a small degree of intermixing of the two phases. This is reflected by the thin line in both Fig. 3(a) and Fig. 3(b), which illustrates the amount of the type 2 phase found in the predominating typel phased sample. By comparing the relative contributions of the two phases to the total integrated intensity of the $\mathrm{O}-\mathrm{H}$ stretch region, we estimate that the sample of predominantly type 1 contains approximately $30 \%$ of type 2 . Lastly, note that the calculations were done in optimized, static, unit-cell geometries and hence cannot capture the unit-cell variations giving rise to the Gaussian-shaped broadenings, nor the finite vibrational lifetime giving rise to Lorentzian-shaped broadenings, in the experimental spectra. Thus, the calculated frequencies should be seen as indications of the frequency range expected from the different atomic positions in the experimental spectra.

\subsection{Host-lattice region of the vibrational spectra}

In Fig. 4 are shown the $50-650 \mathrm{~cm}^{-1}$ range of the $20{ }^{\circ} \mathrm{C}$ Raman spectra of the dehydrated $\left(\mathrm{Ba}_{2} \mathrm{In}_{2} \mathrm{O}_{5}\right)$ and hydrated $\left(\mathrm{BaInO}_{3} \mathrm{H}\right)$ samples. Included in the figure [Fig. 4(b)] is also the spectrum for an intermediate proton loading, as will be discussed in detail below. Considering first the spectrum of the dehydrated material [Fig. 4(a)], we observe several welldefined bands in agreement with the literature. These bands are assigned according to the following: (i) bands below $200 \mathrm{~cm}^{-1}$ relate to vibrational modes involving the heavy Ba ions, (ii) bands between 200 and $350 \mathrm{~cm}^{-1}$ relate to different tilt and bend modes of the $\mathrm{InO}_{4}$ and $\mathrm{InO}_{6}$ moieties, and (iii) bands between 350 and $650 \mathrm{~cm}^{-1}$ relate to symmetric InO stretch modes of the same moieties. ${ }^{7}$ The only discrepancy from this classification regards two In related bands at approximately $60 \mathrm{~cm}^{-1}$ and $130 \mathrm{~cm}^{-1}$ (indicated by vertical lines), 


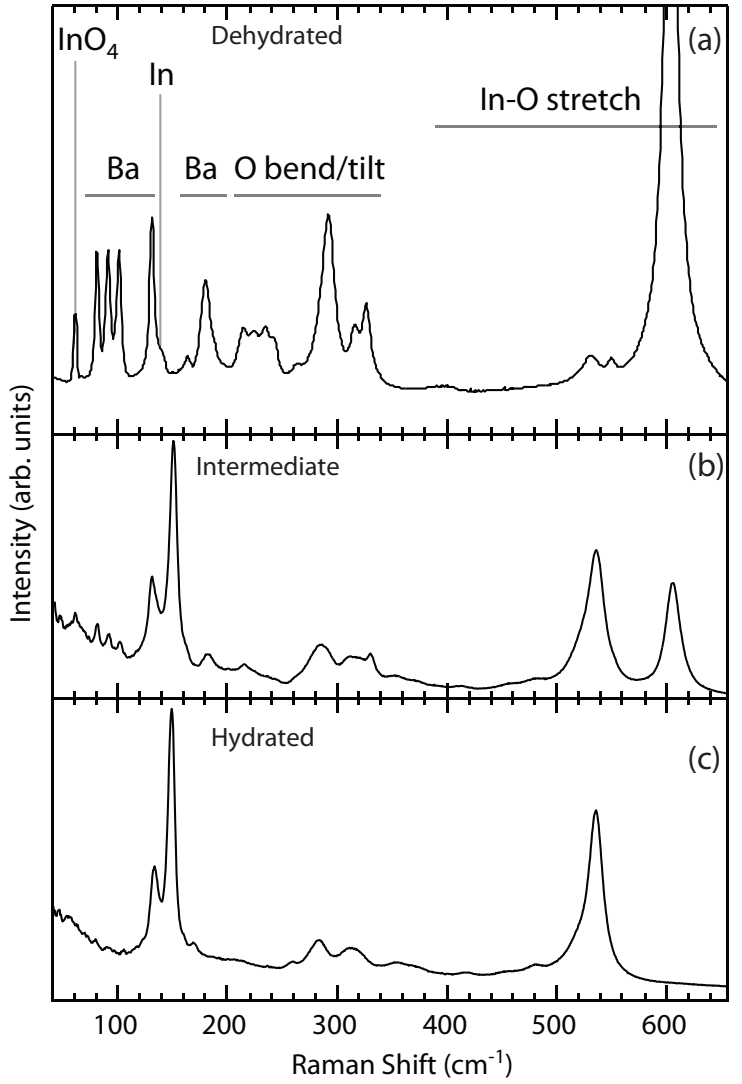

Fig. 4 Raman spectra a measured at $20{ }^{\circ} \mathrm{C}$ of (a) dehydrated, (b) intermediate, and (c) hydrated phases of $\mathrm{Ba}_{2} \mathrm{In}_{2} \mathrm{O}_{5}$. The atomic motions assigned to the vibrational bands in the dehydrated phase are indicated. The detailed vibrational assignment can be found in $\mathrm{Bi}$ elecki et al. ${ }^{7}$.

respectively.

Considering next the spectrum of the hydrated material [Fig. 4(c)], we observe that the spectrum changes considerably upon hydration. This is expected since the overall structure changes from a brownmillerite to a perovskite-like structure. In particular, we observe that all Ba related bands, except the one at $130 \mathrm{~cm}^{-1}$, as well as the strong $600 \mathrm{~cm}^{-1}$ band, which is assigned to In-O stretches of $\operatorname{In}(2) \mathrm{O}(2)_{2} \mathrm{O}(3)_{2}$ tetrahedra, are now completely absent. Instead, a strong band at around $530 \mathrm{~cm}^{-1}$, which is assigned to In-O stretches of $\mathrm{InO}_{6}$ octahedra, and a band at $150 \mathrm{~cm}^{-1}$, are now observable in the spectrum. The $150 \mathrm{~cm}^{-1}$ band has previously been assigned to an $\operatorname{In}(1)$ related mode activated by the long-range non-centrosymmetric distortion of the $\operatorname{In}(1) \mathrm{O}(2)_{2} \mathrm{O}(1)_{4}$ octahedra, as caused by the hydrogen bonding between $\mathrm{H}(1)$ protons and $\mathrm{O}(1)$ oxygens, which is a fingerprint of the Martinez1 proton configuration. ${ }^{7}$ Further information about the non-centrosymmetric $\operatorname{In}(1) \mathrm{O}(2)_{2} \mathrm{O}(1)_{4}$ distortion can be found in the linewidths of the 150 and $530 \mathrm{~cm}^{-1}$ bands as a function of temperature, as we shall see later but first we discuss the overall spectral changes with increasing temperature.

Figure 5 shows the Raman spectra measured upon increasing the temperature from $20{ }^{\circ} \mathrm{C}$ to $600{ }^{\circ} \mathrm{C}$. For the $50-720$ $\mathrm{cm}^{-1}$ range of the spectra [Fig. 5(a)], which relates to the vibrational dynamics of the oxide lattice, we observe a general broadening of all bands as a function of increasing temperature from $20^{\circ} \mathrm{C}$ to $370{ }^{\circ} \mathrm{C}$. At a temperature of $370-380^{\circ} \mathrm{C}$ the spectrum changes more markedly. Most noticeable is the appearance of new, rather strong, bands, at approximately 60,82 , $92,102,180$ and $620 \mathrm{~cm}^{-1}$, as well as of weaker bands in the range $215-243 \mathrm{~cm}^{-1}$, suggesting a structural phase transition away from the structure of the (fully) hydrated material. In this context, the $60 \mathrm{~cm}^{-1}$ and $620 \mathrm{~cm}^{-1}$ bands are identified as tilt motions and symmetric In-O stretches of $\operatorname{In}(2) \mathrm{O}(2)_{2} \mathrm{O}(3)_{2}$ tetrahedra, respectively. ${ }^{7}$ The appearance of these bands is in agreement with the concomitant transformation of $\mathrm{InO}_{6}$ octahedra to $\mathrm{InO}_{4}$ tetrahedra as the sample is dehydrated with increasing temperature. ${ }^{7}$ The other bands relate to vibrations involving mainly the $\mathrm{Ba}$ ions $\left(82,92,102\right.$, and $180 \mathrm{~cm}^{-1}$ ) and oxygen ions (215-243 $\mathrm{cm}^{-1}$ ), respectively, further reflecting the structural change. Upon further temperature increase (from $370{ }^{\circ} \mathrm{C}$ to $600{ }^{\circ} \mathrm{C}$ ), the spectrum changes smoothly towards the shape of the spectrum for the dehydrated material, although it should be noted the fully dehydrated phase was not reached within the covered temperature range. In particular, the symmetric In-O stretch band at $620 \mathrm{~cm}^{-1}$ band downshifts gradually with increasing temperature to reach a position of $595 \mathrm{~cm}^{-1}$ at $600{ }^{\circ} \mathrm{C}$. Thermal broadening is responsible for reducing the spectral intensities at higher temperatures compared to the fully dehydrated $20^{\circ} \mathrm{C}$ spectra shown in Fig. 4(a).

In this context, we now turn to the temperature dependence of the linewidths of the two $\operatorname{In}(1)$ related bands at 150 and $530 \mathrm{~cm}^{-1}$, which are associated with the noncentrosymmetric $\mathrm{In}(1) \mathrm{O}(2)_{2} \mathrm{O}(1)_{4}$ distortion in $\mathrm{BaInO}_{3} \mathrm{H}$. The thermal linewidth broadening is given by the Klemens model, which takes into account the anharmonic decay of one optical phonon into two acoustic phonons. ${ }^{14}$ By this process the linewidth, $\Gamma$, increases with temperature according to $\Gamma(T) \approx$ $\Gamma(0)\left[1+2 /\left(\exp \left(\hbar \omega_{0} / 2 k_{B} T\right)-1\right)\right]$, where $\omega_{0}$ is the frequency of the optical phonon. Deviations from this rule are a sign of additional processes that decrease the phonon lifetime $\tau$ $(\tau \approx 1 / \Gamma)$ and broadens the vibrational linewidth. Such broadening commonly arises from increased disorder, and consequently anharmonicity, of the atomic species involved in the vibration at hand. ${ }^{15,16}$

In Fig. 6(a-b) are shown the temperature evolution of the 150 and $530 \mathrm{~cm}^{-1}$ linewidths, together with fits to the Klemens model (solid lines). As can be seen, the measured linewidths agree well with the Klemens model until a temperature of $c a .370{ }^{\circ} \mathrm{C}$ is reached, indicating no loss of coher- 


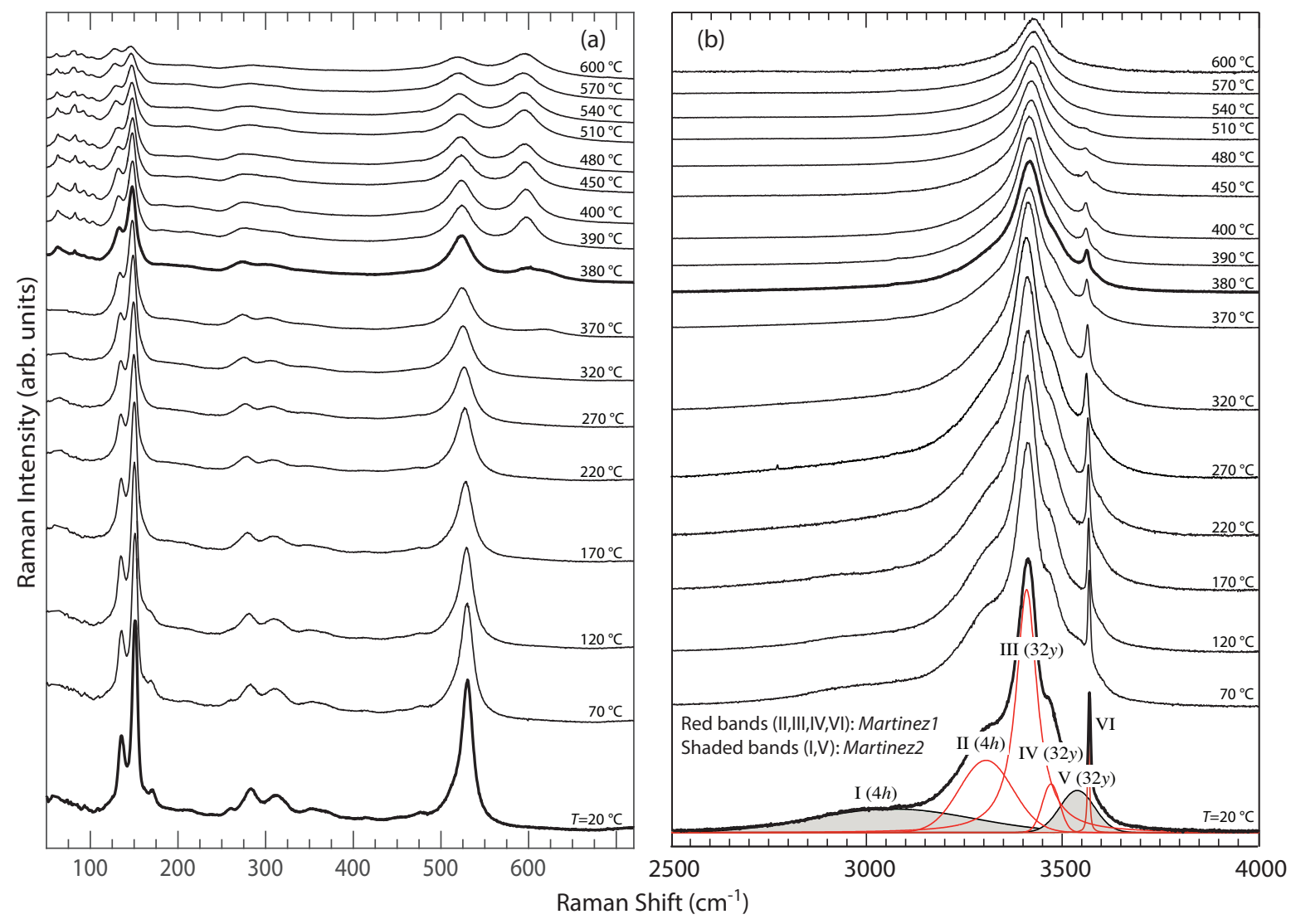

Fig. 5 (Color online) Variable temperature Raman spectra measured in-situ in (a) the lattice and (b) the O-H stretch frequency region, respectively. The spectra distinguished with thick lines indicate the fully hydrated sample and the appearance of the intermediate phase. Included in (b) is the peak fitted components of the O-H stretch spectrum, where the bands II, III, IV and VI (in red color) are suggested to relate to the Martinez 1 structure and the bands I and V (shaded) are suggested to relate to the Martinez2 structure.

ence in the $\operatorname{In}(1) \mathrm{O}(2)_{2} \mathrm{O}(1)_{4}$ distortion below $370{ }^{\circ} \mathrm{C}$. Above $370{ }^{\circ} \mathrm{C}$, however, both modes show an anomalous increase of $\Gamma$ with increasing temperature. This is a clear indication of decoherence in the $\operatorname{In}(1) \mathrm{O}(2)_{2} \mathrm{O}(1)_{4}$ distortion, which we interpret as due to the gradual dehydration above $370{ }^{\circ} \mathrm{C}$, which is illustrated in Fig. 6(c).

Our results support the following interpretation of the hydrated-to-intermediate phase transition. Heating the sample from $20^{\circ} \mathrm{C}$ gradually releases protons and oxygen atoms from the sample, a process during which $\operatorname{In}(2) \mathrm{O}(2)_{2} \mathrm{O}(3)_{4}$ octahedra are transformed into $\operatorname{In}(2) \mathrm{O}(2)_{2} \mathrm{O}(3)_{2}$ tetrahedra. However, enough $\operatorname{In}(2) \mathrm{O}(2)_{2} \mathrm{O}(3)_{4}$ octahedra are still present in order to keep the overall symmetry of the hydrated phase. The sudden spectral changes at $370{ }^{\circ} \mathrm{C}$ suggest a change in symmetry throughout the sample, and indicates that the density of $\operatorname{In}(2) \mathrm{O}(2)_{2} \mathrm{O}(3)_{2}$ tetrahedra has grown enough to transform the $\mathrm{O}(3)$ layer symmetry to that of the dehydrated phase. Thus, the intermediate structure is distinctly different from the dehydrated structure in that, even though the crystal structure ap- proaches the symmetry of the dehydrated structure upon dehydration, the non-centrosymmetric $\operatorname{In}(1) \mathrm{O}(2)_{2} \mathrm{O}(1)_{4}$ distortion and its associated vibrational modes at 150 and $530 \mathrm{~cm}^{-1}$ are still present.

\subsection{O-H stretch region of the vibrational spectra}

The gradual dehydration upon increasing temperature is consistent with the spectral changes in the $\mathrm{O}-\mathrm{H}$ stretch region [Fig. 5(b)], which reflects a change in the local coordination of protons in the material. In particular, one should note that the frequency of an O-H stretch mode is very sensitive to the degree of hydrogen bonding the proton may experience towards a neighboring oxygen and that such a hydrogen-bonding interaction generally softens the mode. ${ }^{17}$ Analysis of the $\mathrm{O}-\mathrm{H}$ stretch band/s provides therefore a spectroscopic means not only to identify, but also to distinguish between different proton sites in the structure. The very broad, asymmetric, $\mathrm{O}-\mathrm{H}$ stretch band for $\mathrm{BaInO}_{3} \mathrm{H}$ suggests that several different pro- 


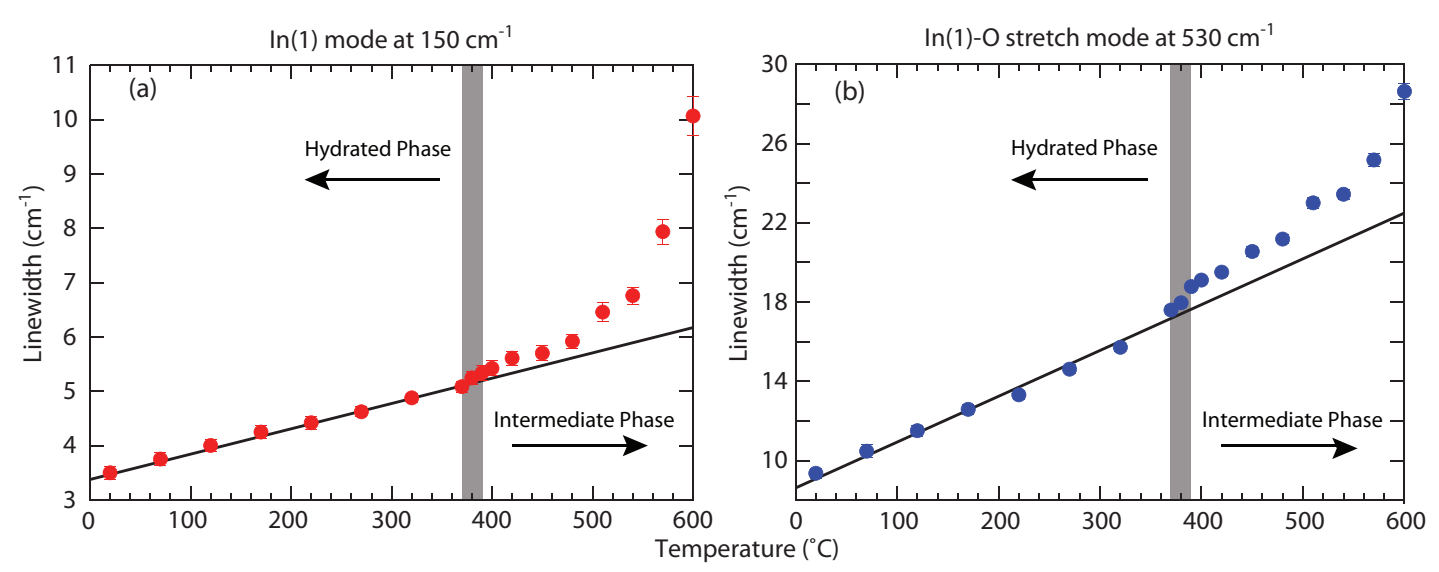

(c)

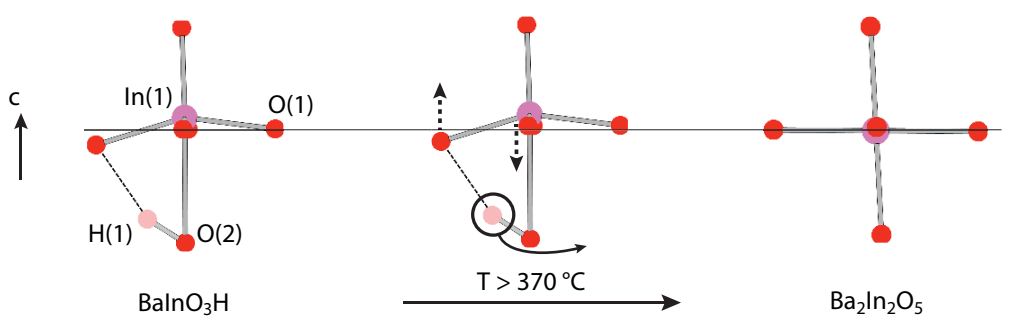

Fig. 6 (Color online) Temperature dependence of the spectral linewidth (full width at half maximum) of (a) the In(1) mode at $150 \mathrm{~cm}^{-1}$ and (b) the $\operatorname{In}(1)-\mathrm{O}(1)$ stretch mode at $530 \mathrm{~cm}^{-1}$. The anomalous increase in linewidth above the hydrated-to-intermediate phase transition is attributed to a gradual decoherence of the non-centrosymmetric distortion of the $\operatorname{In}(1) \mathrm{O}(2)_{2} \mathrm{O}(1)_{4}$ octahedra as $\mathrm{H}(1)$ protons are released; this is depicted schematically in (c). The non-centrosymmetric distortion is highlighted by the solid line that passes through the octahedral inversion plane. It is clear that the $\mathrm{In}(1)$ and $\mathrm{O}(1)$ positions in $\mathrm{BaInO}_{3} \mathrm{H}$ (left) break the inversion symmetry, as opposed to the situation in $\mathrm{Ba}_{2} \mathrm{In}_{2} \mathrm{O}_{5}$ (right). As the material is dehydrated, the inversion symmetry reappears gradually throughout the sample and follows the anomalous increase in vibrational linewidths (middle).

ton sites are present. This is opposed to only one, well defined, proton site, which should be reflected by one, relatively sharp, $\mathrm{O}-\mathrm{H}$ stretch band. A peak fit analysis suggests that we can reproduce the $\mathrm{O}-\mathrm{H}$ stretch band by four Gaussian components at $3050,3310,3470$, and $3540 \mathrm{~cm}^{-1}$ (marked as I, II, IV, and $\mathrm{V})$, and two Lorentzian components at 3410 and $3570 \mathrm{~cm}^{-1}$ (marked as III and VI), hence suggesting that there are six distinctly different proton sites in the material. A comparison with Fig. 3(b) would suggest that bands II, III, IV and VI (in red) relate to the proton configuration according to typel, i.e. the Martinez 1 structure, whereas bands I and V (in black) relate to the proton configuration according to type2, i.e. the Martinez2 structure. From the calculated spectra shown in Fig. 3 we also can see that $\mathrm{O}-\mathrm{H}$ stretch vibrations involving $\mathrm{H}(1)$ protons are of higher frequency compared to the ones involving the $\mathrm{H}(2)$ protons. Because of this, we attribute band III and IV to $\mathrm{H}(1)$ protons at the $32 y$ position and band II to $\mathrm{H}(2)$ protons at the $4 h$ position, $c f$. Fig. 1.

Although the intensities of the different O-H stretch components provides a direct indication of the relative occupation of protons in the different sites, a quantitative assessment of the integrated intensity of the $\mathrm{O}-\mathrm{H}$ stretch band/s is, generally, not straightforward, since the Raman scattering cross section may vary with the degree of hydrogen bonding, i.e. with the frequency of the vibration. In order to elucidate the possible frequency dependency of the Raman scattering cross section, we also measured the $\mathrm{O}-\mathrm{H}$ stretch region using INS, for which the intensity of a particular vibration is directly proportional to the number of vibrating species, irrespective of their vibrational frequency. ${ }^{18}$ A comparison of the Raman and INS spectra is shown in Fig. 7. As can be seen, the shape of the O-H stretch band, measured with the two techniques, is indeed similar to each other, suggesting that there is no strong dependence of the Raman scattering cross section with the frequency of the $\mathrm{O}-\mathrm{H}$ stretch vibrations in the material as studied here. Consequently, we can directly translate the area under each O$\mathrm{H}$ stretch component in Fig. 5(b) to a corresponding "bandresolved" hydration level. Fig. 8(a) shows the normalized hydration level for each $\mathrm{O}-\mathrm{H}$ stretch component together with the overall hydration level as determined by thermal gravimetric 


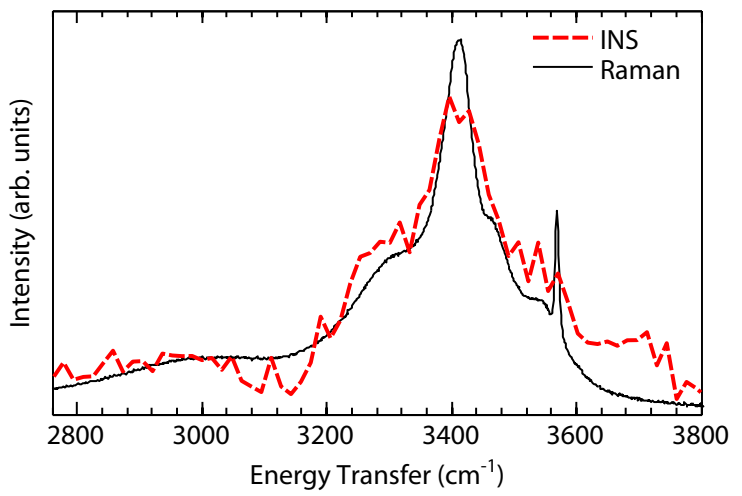

Fig. 7 (Color online) Comparison between the $\mathrm{O}-\mathrm{H}$ stretch region of the Raman and INS spectra of $\mathrm{BaInO}_{3} \mathrm{H}$. The Raman spectrum was measured at room temperature, whereas the INS spectrum was measured at $10 \mathrm{~K}$.

measurements under similar conditions. As can be seen, the hydrated-to-intermediate phase transition corresponds to a hydration level of approximately $50 \%$, for all six bands. That is, the protons are homogeneously desorbed over the oxide lattice, with essentially the same desorption rates for protons on the $4 h$ and $32 y$ sites and for both phases (typel and type2. Above the phase transition temperature, however, protons on the $4 h$ site are preferentially desorbed and hence the relative portion of protons on the $32 y$ position in the material increases drastically. This is further illustrated in Fig. 8(b), where also the temperature dependence of the relative amounts of the two phases are presented. Importantly, we find that, below the phase transition temperature, our specific sample consists of roughly $3 / 4$ of phase type 1 and $1 / 4$ of phase type2, whereas above the phase transition temperature there is a preferential desorption of protons in type 2 . At above $500{ }^{\circ} \mathrm{C}$, all protons originating in phase type 2 are gone.

To summarise our findings, it is suggested that at room temperature the $\mathrm{BaInO}_{3} \mathrm{H}$ sample is composed of two distinct phases (3/4 of phase type 1 and $1 / 4$ of phase type 2 ), which are attributed to the two lowest-energy proton configurations Martinez1 and Martinez2. Both of the phases are characterised by two main proton positions ( $4 h$ and $32 y$ ), which are equally occupied but differ in the way the protons on the $32 y$ site are hydrogen bonded. Upon increasing the temperature to $370{ }^{\circ} \mathrm{C}$, the material dehydrates essentially homogeneously, meaning that the two proton positions are gradually depleted at a rate that is almost the same in both phases. Upon further temperature increase, the dehydration process is more complicated as it is characterised not only by a dehydration rate which differs between the two phases but is also different for the two proton positions. For phase typel the $4 h$ proton position is depleted at a rate that is higher than for the $32 y$ proton position. For
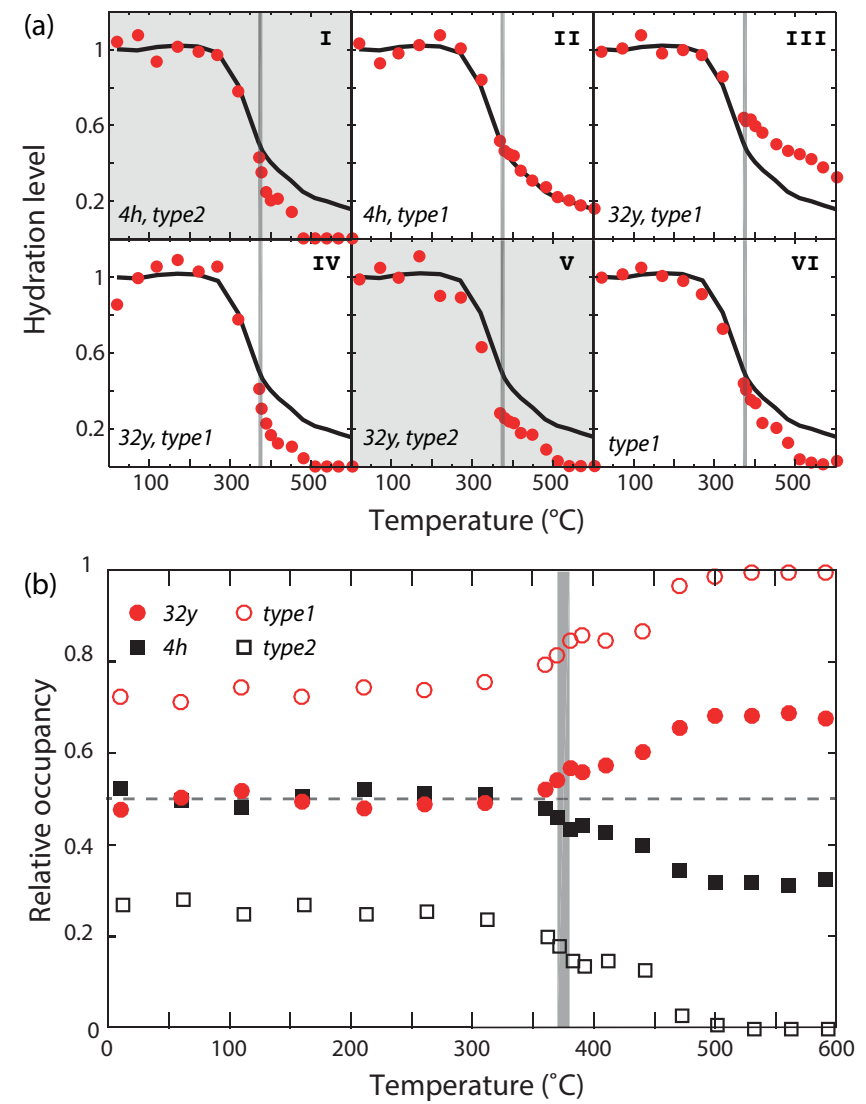

Fig. 8 (Color online) (a) Hydration levels within the six O-H stretch bands (red circles). As a reference, the solid black lines show the overall hydration level in the sample as determined by thermal gravimetric analysis, $c f$. Fig. 2 . The corresponding proton position ( $4 h$ or $32 y$ ) and initial phase (typel or type 2) is indicated for each band. In (b) we show the distribution of protons between the different proton positions and initial hydration phases. As expected, the fully hydrated sample has essentially equally many protons in the $4 h$ and $32 y$ positions. Passing through the hydrated-to-intermediate phase transition results in faster release of protons on the $4 h$ site as compared to protons on the $32 y$ site. Similarly, protons originating in the type 1 phase are overall more thermally stable compared to those originating in type 2 . The vertical shaded lines indicate the structural phase transition between the hydrated and intermediate phases.

phase type 2 , both proton sites dehydrate at an almost equal rate. This dehydration mechanism is summarized graphically in Fig. 9, where we have combined thermal gravimetric and Raman data in order to extract individual dehydration curves for the typel and type 2 phases.

Our new insight into the dehydration mechanism of $\mathrm{BaInO}_{3} \mathrm{H}$ also provides ideas relevant to a more mechanistic understanding of the proton dynamics, i.e. of the proton conduction mechanism, in the material. In particular, we suggest 
that the $\mathrm{H}(1)$ protons on the $32 y$ position in the energetically more stable phase type 1 are less mobile than the protons in the other local structural configuration. This indicates that above the hydrated-to-intermediate phase transition at $370{ }^{\circ} \mathrm{C}$, there is an inhomogeneous proton conduction mechanism in which the protons move more easily within the $\operatorname{In}(2) \mathrm{O}(3)_{4}$ planes of the material, whereas for lower temperatures, the larger occupation of $\mathrm{H}(2)$ protons on the $4 h$ position may hinder significantly the proton diffusion within these planes. This picture is in agreement with the dehydration behaviour of phase type2, but here the different hydrogen-bond pattern of the $\mathrm{H}(1)$ protons on the $32 y$ position appears to have a crucial effect as it make these protons more mobile.

A plausible reason for the energetically higher stability of the phase typel, and in particular for the corresponding $32 y$ protons, may be that the non-centrosymmetric distortion of the $\operatorname{In}(1) \mathrm{O}(2)_{2} \mathrm{O}(1)_{4}$ octahedra creates a well-defined local energy minimum for the $\mathrm{H}(1)$ protons. This is in agreement with the relatively narrow linewidth of band III, see Fig. 5(b). This does not necessarily mean that the phase typel reflects the global ground state, but perhaps a metastable state whose portion depends on how the sample is hydrated. Although we are unable to determine precisely the factors determining the ratio of the two phases, our results provide some hints as to why the two phases can coexist. On the one hand, we have a spectrally well-defined proton configuration, typel, whereas on the other hand, we have the type 2 configuration which is featured by generally broader spectroscopic features and thus a higher degree of structural variability in the material. This may be indicative of a competition between energy and entropy at play, where the parameters of the hydration (e.g. temperature, and time) may tip the balance of the two. To this end, an investigation of the vibrational spectra as a function of systematic changes of the hydration conditions is likely to be beneficial for the clarification of the structure determining mechanisms involved, particularly if coupled to mechanistic studies of proton diffusion, using e.g. quasielastic neutron scattering. ${ }^{19}$

\section{Conclusions}

To conclude, we find that the proton conducting oxide $\mathrm{Ba}_{2} \mathrm{In}_{2} \mathrm{O}_{5}\left(\mathrm{H}_{2} \mathrm{O}\right)_{x}$ adopts three distinctly different local structures, depending on the level of hydration, $x$, and temperature, $T$. The structure evolves from a perovskite-like structure for the fully hydrated material $(x=1)$ at $T=20^{\circ} \mathrm{C}$, through a partially hydrated structure for $20{ }^{\circ} \mathrm{C}<T<600{ }^{\circ} \mathrm{C}$, to a brownmillerite-like structured, essentially proton-free, material, at even higher temperatures. The structure of the intermediate phase is similar to the structure of the dehydrated material, but with the difference that it is characterised by a non-centrosymmetric distortion of the $\mathrm{InO}_{6}$ octahedra not present in the latter. The hydrated-to-intermediate phase tran-

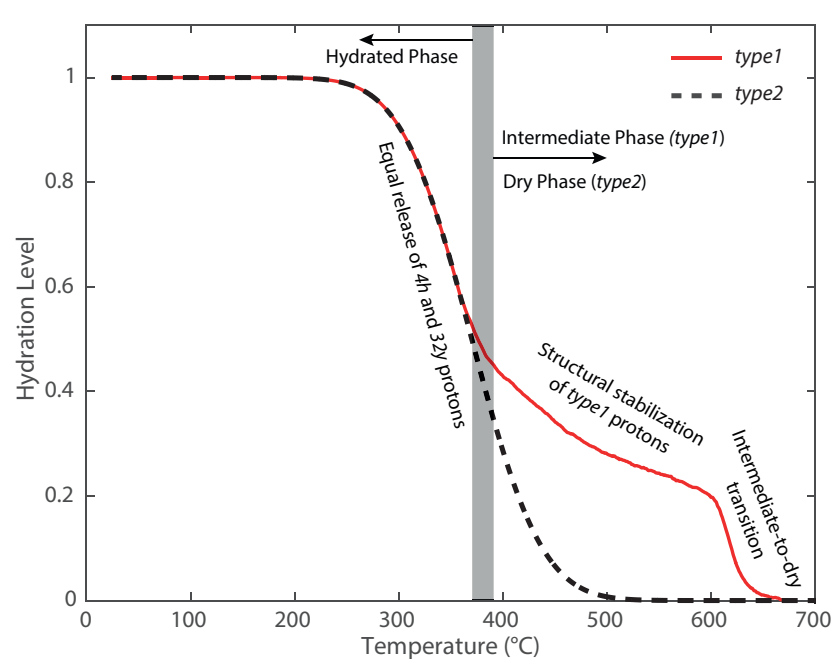

Fig. 9 (Color online) Schematic depiction of the dehydration mechanism in the type 1 and type 2 phases of $\mathrm{BaInO}_{3} \mathrm{H}$. Above $370{ }^{\circ} \mathrm{C}$, within the hydrated regime, $4 h$ and $32 y$ protons are released at equal rates in both phases, type 1 and type 2 . In phase type 2 , this remains true over the complete dehydration range until the completely dehydrated $\mathrm{Ba}_{2} \mathrm{In}_{2} \mathrm{O}_{5}$ phase is reached at approximatively $500{ }^{\circ} \mathrm{C}$. The proton configuration in phase type 1 is such that the protons help in stabilizing the non-centrosymmetric distortion, and the dehydration rate above $370{ }^{\circ} \mathrm{C}$ is thus lower in phase type 1 as the protons are structurally stabilized within the crystal structure. We attribute this as the cause for the presence of the intermediate phase observed between 370 and $600{ }^{\circ} \mathrm{C}$ in phase type 1 . The sudden drop in hydration level around $600{ }^{\circ} \mathrm{C}$ indicates an intermediate-to-dehydrated phase transition.

sition occurs at approximately $370{ }^{\circ} \mathrm{C}$, which corresponds to approximately $50 \%$ dehydration. Up to this temperature, the dehydration process progresses uniformly, with equal release of protons from the $4 h$ and $32 y$ proton positions, whereas upon further temperature increase protons on the $4 h$ position are released at a higher rate. We also found that the $\mathrm{O}-\mathrm{H}$ stretch region of the vibrational spectra is not consistent with a singlephase spectrum, but is in agreement with the intermixture of spectra associated with the lowest-energy (typel) and nextlowest-energy (type 2) proton configurations in the structure of the material. During dehydration we find protons in crystallographic sites associated with typel to have higher thermal stability compared to those associated with type 2 . The amount of each phase is found to depend on how the material is hydrated and it is thus possible that the hydration conditions influence the proton conductivity at intermediate temperatures. 


\section{Acknowledgements}

Funding from the Swedish Research Council (grant No. 20103519 and 2011-4887) is gratefully acknowledged. The STFC Rutherford Appleton Laboratory is thanked for access to neutron beam facilities. We also thank S. M. H. Rahman at Chalmers University of Technology for the preparation of the sample.

\section{References}

1 K. D. Kreuer, Annu. Rev. Mater. Res., 2003, 33, 333-359.

2 L. Malavasi, C. A. J. Fisher and M. S. Islam, Chem. Soc. Rev., 2010, 39, 4370.

3 A. A. Colville and S. Geller, Acta. Crystallogr., Sect. B: Struct. Sci., 1971, 27, 2311-2315.

4 N. Tarasova, I. Animitsa, T. Denisova and R. Nevmyvako, Solid State Ion., 2015, 275, 47-52.

5 R. Dervişoğlu, D. Middlemiss, F. Blanc, Y.-L. Lee, D. Morgan and C. P. Grey, Chem. Mater., 2015, 27, 38613873.

6 R. Dervişoğlu, D. S. Middlemiss, F. Blanc, L. A. Holmes, Y.-L. Lee, D. Morgan and C. P. Grey, Phys. Chem. Chem. Phys., 2014, 16, 2597-2606.

7 J. Bielecki, S. F. Parker, D. Ekanayake, S. M. H. Rahman, L. Börjesson and M. Karlsson, J. Mater. Chem. A, 2014, 2, 16915-16924.

8 A. Mancini, J. F. Shin, A. Orera, P. R. Slater, C. Tealdi, Y. Ren, K. L. Page and L. Malavasi, Dalton Trans., 2012, 41, 50-53.

9 J. F. Shin, D. C. Apperley and P. R. Slater, Chem. Mater., 2010, 22, 5945-5948.

10 J. F. Shin, L. Hussey, A. Orera and P. R. Slater, Chem. Commun., 2010, 46, 4613-4615.

11 J.-R. Martinez, C. E. Mohn, S. Stoelen and N. L. Allan, J. Solid State Chem., 2007, 180, 3388.

12 V. Jayaraman, A. Magrez, M. Caldes, O. Joubert, F. Taulelle, J. Rodriguez-Carvajal, Y. Piffard and L. Brohan, Solid State Ionics, 2004, 170, 25.

13 S. F. Parker, D. Lennon and P. W. Albers, J. Appl. Spectrosc., 2011, 65, 1325-1341.

14 P. G. Klemens, Phys. Rev., 1966, 148, 845.

15 C. H. Perry and R. P. Lowndes, J. Chem. Phys., 1969, 51, 3648.

16 W. Hayes and R. Loudon, Scattering of light by crystals, John Wiley and Sons, New York, 1978.

17 M. Karlsson, M. E. Björketun, P. G. Sundell, A. Matic, G. Wahnström, D. Engberg, L. Börjesson, I. Ahmed, S. G. Eriksson and P. Berastegui, Phys. Rev. B, 2005, 72, 094303: 1-7.
18 M. Karlsson, Dalton Trans., 2013, 42, 317-329.

19 M. Karlsson, Phys. Chem. Chem. Phys., 2015, 17, 26.

| $1-11$ 


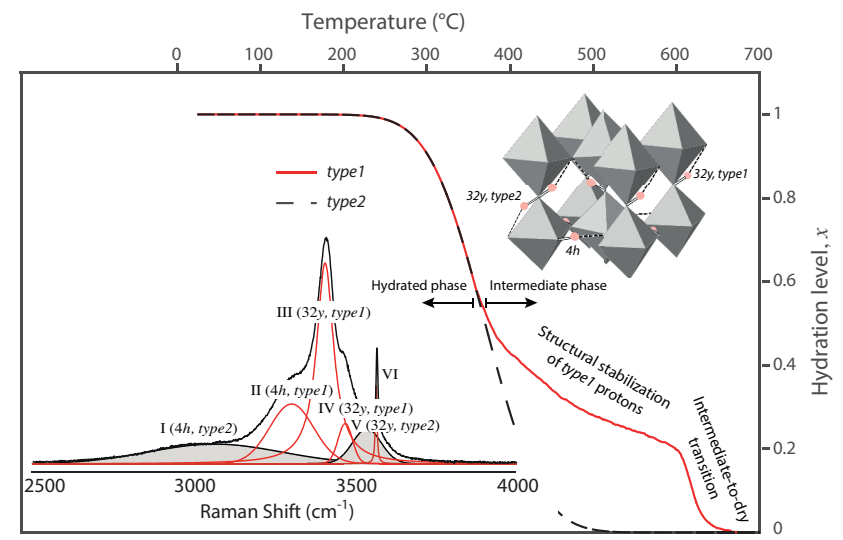

Fig. 10 TOC. Dehydration mechanism of the proton conducting oxide $\mathrm{Ba}_{2} \mathrm{In}_{2} \mathrm{O}_{5}\left(\mathrm{H}_{2} \mathrm{O}\right)_{x}$. 